\title{
O DESASSOSSEGO NARRATIVO NA INFÂNCIA DA MODERNIDADE: uma leitura hipertextual de lnfância Berlinense: 1900
}

\author{
Claudia Luiza Caimi \\ (UFRGS) \\ Henrique Lima Araujo \\ (UFRGS)
}

\section{RESUMO}

Este trabalho tem como objeto Infância berlinense: 1900, de Walter Benjamin. O livro contém 42 quadros imagéticos, nos quais o filósofo busca retratar a burguesia alemã do início do século XX sob o ponto de vista da criança que fora. No entanto, o autor abandona o projeto autobiográfico tradicional e linear, pois entende que a memória não é coesa e que o passado é sempre articulado. Dessa forma, Benjamin constrói em Infância berlinense: 1900 uma narrativa constelacional, fragmentada e descontínua, que pode ser lida de forma hipertextual. Assim, este trabalhou busca desenvolver a narrativa do hipertexto neste livro, associando as suas diversas imagens. Para isso, construiu-se o site literateias.com. br, onde o livro foi disponibilizado com hiperlinks que unem os quadros uns aos outros. Desenvolveu-se também a ideia de que esta narrativa descontínua é marca do sujeito moderno, que é descentrado e fragmentado, e que tem seu nascimento ainda no século XIX. Concluiu-se, por fim, que o hipertexto ocorre também em textos impressos, e que é característica dos questionamentos trazidos pela modernidade, como o fim das grandes narrativas. A diferença é que os hipertextos atuais possuem um suporte ideal, a saber, a tela do computador, que potencializa os recursos e as associações que os constituem. Nesse sentido, a construção do site literateias.com.br evidenciou o caráter hipertextual de Infância berlinense: 1900 ao mesmo tempo em que trouxe um novo fôlego à obra benjaminiana, que pode ser reinterpretada à luz desse novo suporte. PALAVRAS-CHAVE: Walter Benjamin. Hipertexto. Narração moderna. Leitura. literateias.com.br. 
Muito antes do advento da internet, alguns escritores já estavam construindo em seus livros teias semelhantes às virtuais. Sem início pré-estabelecido e sem qualquer tipo de linearidade, esses textos eram estruturados de forma constelacional, convidando os leitores a adentrarem em um labirinto para encontrar suas próprias estrelas e fazer as suas associações. O hipertexto - esse texto que temos todos os dias na internet -, então, já começava a ter o seu início ainda na literatura impressa. É o caso, por exemplo, de Cortázar com seu Jogo da Amarelinha; do Livro do Desassossego, de Fernando Pessoa; ou ainda d'As Cidades Invisiveis, de Calvino.

Pensando em potencializar os escritos que já estavam arquitetados no modelo de redes que o site literateias.com.br foi criado. Nosso objetivo não é transformar textos literários em hipertextos, mas experimentar esse novo suporte, que é a tela do computador, pois pensamos que, assim, sentidos que não se apresentam no livro impresso podem ser manifestados. O primeiro livro do projeto foi Infância berlinense: 1900, do filósofo alemão Walter Benjamin. Seguindo essa lógica hipertextual, o livro traz fragmentos de memória que buscam retratar a burguesia alemã do início do século XX, sob o ponto de vista da criança que Benjamin fora.

Em 1932, a partir de um convite de um jornal alemão, Benjamin lançou-se na elaboração de Infância berlinense: $1900^{1}$. Até a sua morte, em 1940, o filósofo escreveu e reescreveu os quadros de sua infância, ora diminuindo-os, ora expandindo-os, além de excluir alguns e mudar a ordem do livro, mas nunca chegando a nenhuma versão definitiva. Segundo Barrento:

A Infância berlinense é provavelmente o caso editorial e filológico mais complexo de todos os textos de Walter Benjamin (...). Esse livro é, de fato, um complexo movediço e mutante de textos, no que se refere à sua ordenação, seleção, versões, variantes e posicionamento narrativo (2013, p. 134).

Na lida dos anos 1930, portanto, Benjamin redige um livro de memórias, mas nem por isso um livro memorialístico. A preocupação não é saudosista, mas histórica; ou seja, tem mais relação com a sociedade do que nostalgia com o sujeito que recorda. Não se trata de lembrar o passado como ele foi, pois esse resgate exato é impossível; trata-se, isso sim, de articular o passado, decifrá-lo, desenvolvê-lo, atravessando o consciente e, por consequência, alterando o presente daquele que rememora: 
Walter Benjamin compreendia a memória não como a posse do rememorado - um ter, uma coleção de coisas passadas -, mas como uma aproximação sempre dialética da relação das coisas passadas a seu $l u$ gar (...) Deduzia disso (de maneira muito freudiana, por sinal) uma concepção da memória como atividade de escavação arqueológica, em que o lugar dos objetos descobertos nos fala tanto quanto os próprios objetos (DIDI-HUBERMAN, 2010, p. 174).

Nesse sentido, a formação de uma imagem a partir desse movimento de memória ocorre de forma dialética. $\mathrm{O}$ conceito de imagem dialética em Walter Benjamin é construído a partir de um diálogo entre o esquecido e o lembrado, isto é, a imagem contém em sua própria constituição um conflito, uma tensão entre passado apagado e passado iluminado, como se existissem dois lados de uma face cujo acesso está restrito a apenas um. Há sempre duas imagens na imagem dialética, unidas por um fio subterrâneo: a que foi esquecida e, portanto, perdida no inconsciente, e a sua substituta, a possível de ser evocada, quase uma lembrança falsa (CHAVES, 1999). A imagem da memória não surge nítida, mas nebulosa, e a tentativa de estruturá-la em linguagem também é um esforço de atribuição de sentido, num processo semelhante ao que fazemos com os sonhos.

Por serem dialéticas, as imagens formadas em Infância berlinense: 1900 são tão ou mais importantes do que as palavras, pois é a partir delas que o livro ganha as suas formas: a forma fragmentada, no viés narrativo; a forma crítica, no viés histórico. Fragmentada pois ela não produz coesão, mas sim uma estrutura deslizante, sempre aberta e possível de ser desdobrada, contribuindo para uma leitura hipertextual. Sobre isso, afirma Georges Didi-Huberman:

Há de fato uma estrutura em obra nas imagens dialéticas, mas ela não produz formas bem-formadas, estáveis ou regulares: produz formas em formação, transformações, portanto efeitos de perpétuas deformações (2010, p. 173) [grifo do autor].

Por outro lado, a imagem dialética também é crítica porque essa fusão de duas imagens em uma permite olhar a história de uma nova perspectiva, tal qual o osso que, lançado para cima, vira uma nave no início do filme 2001: Uma Odisseia no Espaço, de Stanley Kubrick. Esse movimento dá novos rumos à história na medida em que a interpreta não de forma cronológica, mas de forma associativa, mostrando as relações que os fatos sociais e culturais têm entre si, ressaltando a importância do lugar em que a imagem emerge, lugar esse que pode dizer tanto quanto a 
própria imagem: "a imagem dialética é exatamente aquilo que produz a história” (DIDI-HUBERMAN, 2010, p.177).

Narrar a memória, portanto, é reescrever a história, é tornar o passado conhecido para reorganizar os rumos do presente e do futuro. Por isso, não temos na obra um eu-lírico subjetivo, preocupado em evocar suas lembranças de infância tal como os poetas românticos do século XIX, mas sim um eu-lírico social, comprometido em olhar a criança e revelar, os comportamentos burgueses da virada do século.

Com isso, o narrador depara-se com um obstáculo: a impossibilidade de narrar, consequência da modernidade, que atrofia a experiência no mundo mecanizado (DIDI-HUBERMAN, 2010). A consolidação do capitalismo e o marco das grandes guerras ocasionam, primeiramente, a fragmentação do sujeito moderno e, por consequência, o declínio da experiência. Esta experiência, que antes era compartilhada e transmitida de geração a geração, transforma-se em vivência, única, individual e intransmissível, impossível de ser partilhada. (BENJAMIN, 1983). As experiências modernas deixam de ser transmissíveis, pois a vida é transformada em algo incerto quando o homem percebe a pobreza de sua experiência, que é pequena e simples.

Esse sujeito isolado não consegue mais narrar: "A perda da experiência acarreta um outro desaparecimento, o das formas tradicionais de narrativa" (GAGNEBIN, 2009, p. 50). É nesse contexto que temáticas como o delírio, o sonho e a memória começam a ser mais presentes na literatura. Isso acontece porque essas categorias se reinventam a cada narração por se mostrarem difusas, incertas e fragmentadas, evidenciando, assim, as falhas da consciência.

Dessa maneira, Benjamin organiza seu projeto em uma estrutura fragmentária, com memórias lampejantes, que são independentes, autônomas. No entanto, há entre elas diversas associações que não estão formuladas, cabendo ao leitor esse trabalho de relacionar os diversos quadros. São "peças de um museu", para usar a expressão de Gagnebin (1994), isto é, essas pequenas narrações estão expostas aos olhos do leitor aparentemente soltas, mas, quando observadas mais atentamente, percebe-se relações, que podem ser históricas, temáticas, espaciais etc. Ou seja, ao mesmo tempo em que são finitas - um número entre 24 e 42 imagens, dependendo da versão -, ao cederem um espaço para além desse sujeito, elas adquirem um caráter infinito em cada leitura. Esse lugar é um vazio em cada imagem e também na composição desse mosaico, que se 
abre em dobras e mais dobras quando se encontra com diferentes leitores, que, além de atribuírem diferentes sentidos em cada leitura, traçam múltiplas associações entre os quadros, como no hipertexto. É como se cada lembrança pudesse ser cavada mais profundamente e se deslocasse por mais espaços nesse "mapa constelacional" à medida em que Benjamin vai escrevendo outras lembranças. Nesse sentido, Infância berlinense: 1900 adquire um caráter de "livro-laboratório" - para lançar mão da expressão de Willi Bolle -, e torna-se uma obra aberta, movediça, pois quanto mais fica constituída, quanto mais é escrita, mais longe está de ser terminada. Por isso, mais do que inacabado, o livro torna-se inacabável.

Com essa configuração de trabalho interminável, Benjamin encontra dificuldades em montar o livro. De 1932 a 1940, o autor mantém correspondência constante com Scholem e Adorno, que leem e comentam os diversos quadros. A troca dessas cartas acarreta cinco versões, sendo que três delas são rejeitadas por editoras alemãs, o que obriga Benjamin a ordenar numericamente e reduzir o número de quadros a fim de conseguir sua publicação.

A importância que Benjamin dá à montagem pode ser vista em outras de suas obras, como, por exemplo, no projeto das Passagens. Willi Bolle (2015) nos mostra a organização feita por Benjamin de um sistema de siglas em cores para um fichário, que recolhia centenas de escritos sobre a cidade de Paris das mais diferentes fontes possíveis, formando uma espécie de "labiríntica enciclopédica":

Benjamin examinou cuidadosamente os 4.234 fragmentos do seu fichário, todos localizáveis alfanumericamente, e selecionou 1.745 deles, ou seja, cerca de $41 \%$ para o seu livro-modelo, indicando à margem destes fragmentos com uma sigla colorida a categoria construtiva na qual cada um deles deveria ser usado (BOLLE, 2015, p. 88).

Esse sistema, ressalta Bolle, reescreve a história, que deixa de ser vista de uma perspectiva cronológica, para ser pensada de forma associativa e reconstitutiva. Para Benjamin, o historiador precisa dar atenção aos cacos, aos resíduos produzidos e preteridos pela história tradicional.

De forma extremamente experimentalista, o livro das Passagens se apresenta como um rascunho ou uma montagem não definitiva se sobrepondo à forma. Dessa maneira, o leitor se vê convidado a praticar uma "leitura ativa de um texto por meio da desconstrução e da montagem" (BOLLE, 2015, p.90), semelhante a um jogo de lego, em que sempre é possível desfazer o já montado para refazer outras construções. Além dis- 
so, essas montagens individuais de cada leitor também poderiam ser feitas nesse sistema sem uma ordem definida, já que a organização não se dá de forma alfanumérica, mas de forma simbólica e colorida. Percebe-se, com isso, que Benjamin eleva o leitor à categoria de protagonista no processo da leitura, colocando o autor em um papel secundário, já que este apenas revela o texto, mas não tem mais domínio de como ele será lido.

Parece óbvio, com isso, que o autor busque incessantemente uma nova forma de escrita que ultrapasse e revigore a escrita tradicional, já que quer dar aos seus livros esse "caráter de canteiro de obras" (BOLLE, 2015), no qual as coisas ainda não estão concluídas e que desvios e mudanças são bem-vindos. Mesmo sem saber, o autor já flertava, seis décadas antes, com essa forma de escrita das sociedades contemporâneas: o hipertexto.

Tendo o pensamento de Benjamin como referência, entendemos o hipertexto como um reflexo da impossibilidade de narrar que, por sua vez, é consequência do advento, em fins do século XIX, da sociedade moderna. As relações políticas evidenciadas por Marx, o inconsciente por Freud, a arbitrariedade linguística por Saussure, as discussões de gênero trazidas pelo movimento feminista, tudo isso afeta o sujeito, que não consegue mais atribuir uma única identidade para si: "as sociedades modernas são, por definição, sociedades de mudança constante, rápida e permanente" (HALL, 2015, p. 12). Portanto, tal qual a sociedade, o sujeito moderno possui como "centro" de sua estrutura um espaço vazio que é preenchido por diversas identidades - por vezes até contraditórias - na medida em que são diversos os mecanismos e as relações sociais. Dessa forma, esse desassossego narrativo que começa no início do século XX encontrará no hipertexto uma estrutura textual que condiz com a sociedade e o sujeito do período e que permanece até hoje: "Trata-se de uma alteridade multilinearizada, fragmentada (...) decorrente de nossas relações atuais com as coisas do mundo" (KOMESU, 2005, p. 108).

Pierre Lévy conceitua hipertexto como um conjunto de "nós - que podem ser palavras, páginas, imagens, gráficos, sequências sonoras ligados por conexões" (1993, p.20). Já para Xavier, hipertexto é "uma forma híbrida, dinâmica e flexível de linguagem que dialoga com outras interfaces semióticas" (2010, p. 208). Ou seja, ambos os autores aceitam a ideia de que, mesmo tendo a tela de computador como suporte ideal, o hipertexto pode funcionar em livros impressos, já que esses nós são blocos de informação que não necessariamente precisam ser digitais. 
Há ainda uma constante entre os autores: o hipertexto é uma estrutura textual associativa, que simula ou reproduz a configuração do pensamento humano. Nesse sentido, pensamos o hipertexto como a narrativa adequada à memória, já que ambos são dispersivos, fragmentados e não-lineares. Lévy (1993) comenta o fato de que a memória retém mais informações organizadas de formas esquemáticas. Então, é como se a memória, que não pode ser evocada de forma clara e linear, se moldasse perfeitamente a este tipo textual que está estruturado espacialmente, sem preocupações com causalidade e linearidade.

Não há início, meio e fim no hipertexto, de maneira que o leitor pode iniciar sua leitura de qualquer ponto sem que isso acarrete prejuízo de sentido, pois não há um eixo estruturante. $\mathrm{O}$ sujeito descentrado passa a ler um texto que também não possui centro: "a não-linearidade sugere o descentramento, isto é, a inexistência de um foco dominante" (KOMESU, 2005, p. 99). Portanto, assim como as imagens de Infância berlinense: 1900, que se abrem em dobras na medida em que cada leitura acontece, o hipertexto é arquitetado de forma constelacional, como uma grande teia em fragmentos, na qual uma informação está associada a outra informação que, por sua vez, liga-se a outra, e assim sucessivamente, em um caminho discursivo plenamente aberto.

Isso gera uma consequência na recepção: o papel do leitor não se restringe a interpretar ou responder ao texto de forma passiva, pois agora ele é capaz também de interferir no próprio texto ao preencher os espaços vazios. Com isso, todo o leitor de um hipertexto é também um coautor, afinal, é ele o responsável pelo bom andamento do texto, definindo, ao final do processo, qual versão que será lida. No entanto, se à primeira vista isso parece ser um movimento de independência na leitura, na prática essa autonomia não é irrestrita. A coautoria está subordinada à autoria, visto que o leitor só pode clicar nos links criados pelo autor, e não em qualquer um. Assim, o leitor ganha liberdade, uma "liberdade possível, mas não a ideal" (XAVIER, 2010, p. 211).

Os livros impressos que são construídos de forma hipertextual, como Infância Berlinense: 1900, por não disporem desses recursos, não possuem hiperlinks formalizados, concretizados, de forma que o próprio leitor precisa construi-los, sendo, portanto, uma leitura mais complexa. Da mesma forma que a criança construída por Benjamin gosta de se ver perdida no labirinto das letras ou de Tiergarten, o leitor do hipertexto não busca se encontrar em uma leitura específica, definindo seu caminho na 
medida em que ele é trilhado: "Acreditamos que a sensação de estar perdido em um hipertexto parece estar relacionada com a tarefa a ser cumprida" (COSCARELLI, 2005, p.115). É como se Benjamin "jogasse" os quadros sem qualquer ordem e organização, e, a partir disso, o leitor se vê obrigado a adentrar esse labirinto para formar a sua própria constelação, a sua própria teia, e atribuir sentido à obra. Como disse Benjamin em relação à criança, perder-se é, enfim, realmente necessário para apreender os sentidos e, com isso, aprender.

Assim, percebemos que poderíamos expor a lógica constelacional da arquitetura de Infância berlinense: 1900 disponibilizando o livro em um suporte digital. Deve ficar claro, então, que a construção do literateias não é um movimento que pretende transformar ou adaptar o livro de Benjamin em hipertexto, pois entendemos que isso já está formulado na escrita original, nos anos 1930. O que pretendemos com o site é potencializar o hipertexto impresso, mudando o seu suporte, já que a tela do computador e a internet radicalizam e tornam mais velozes os deslizamentos associativos existentes no papel, além de permitirem uma leitura "self-service", para usar a ótima expressão de Xavier (2010), na qual o leitor precisa trilhar seu caminho em um labirinto.

A homepage do site é dividida em três faixas: na primeira, encontra-se, do lado esquerdo, a capa da edição de Infância berlinense: 1900 que serviu de base ao processo, e, do lado direito, um texto inicial, que tem como objetivo estimular o hiperleitor a clicar em, pelo menos, algum quadro, e mergulhar na obra de Benjamin. Com o objetivo alcançado, o hiperleitor rola a página e, logo abaixo, encontra a segunda faixa, onde estão distribuídos os hiperlinks de todos os quadros. Essas caixas estão separadas por quatro cores distintas, que mantêm o cuidado da divisão de Benjamin na "versão de última mão". É nessa faixa do site que a recepção da leitura virtual contrasta com a da leitura impressa e tradicional, pois, em um único olhar, o hiperleitor enxerga todos os quadros.

A terceira e última faixa é destinada ao contato com o leitor. Como afirma Willi Bolle (2015), o hipertexto é sempre um "canteiro de obras"; portanto, o site não está concluído nunca. Desta forma, os leitores podem ajudar na construção de novos hiperlinks, ou seja, o literateias.com.br mostra-se receptivo a associações inéditas descobertas por diferentes sujeitos. O lado esquerdo desta última faixa, então, é reservado ao campo de digitação da mensagem. Já no lado direito, encontra-se um texto que tem como objetivo estimular o feedback dos hiperleitores. 
A navegação no site ocorre quando o leitor clica aleatoriamente em um dos quadros do livro. Logo, abrirá na íntegra o texto escolhido, com uma imagem ao fundo. Algumas dessas imagens podem ser trazidas ao primeiro plano por intermédio dos hiperlinks, tornando-se nítidas e se sobrepondo ao texto, como é o caso da estação de Anhalt e da Chausseestrabe, em Partida e Regresso.

Ao final de cada texto, há o mesmo hiperlink: "Selecione outro texto.", para dar a oportunidade ao hiperleitor de voltar ao início e escolher outro caminho. Como o hipertexto assemelha-se aos labirintos infantis de Benjamin, onde o caminho ideal é perder-se, não há prejuízo algum em um possível "começar de novo": "é muito comum o hiperleitor mudar seu objetivo inicial, devido à variedade de blocos de textos que os hipertextos possuem" (PINHEIRO, 2005, p. 140). Com isso, ele pode rever suas estratégias e, a partir disso, construir uma leitura mais eficiente.

Durante o estudo de Infância berlinense: 1900, percebeu-se que as teias construídas por Benjamin são distintas umas das outras e que, portanto, as ligações entre elas no site também deveriam ser. Construíram-se, assim, dois tipos de hiperlinks: o primeiro, que chamamos de passagem, é um hiperlink direto, de um quadro a outro, com associações que podem ser lexicais ou temáticas; o segundo, denominado leque, abre para diversas possibilidades de escolha, todas relacionadas com o clique.

As passagens são os hiperlinks mais explícitos. Essas associações encontradas em Infância berlinense: 1900 reforçam o caráter hipertextual da obra e a tentativa de Benjamin de construir uma espécie de mapa, onde cada quadro poderia conectar-se a outro de forma esquemática. As passagens lexicais são mais evidentes, possíveis de serem feitas ainda em uma primeira leitura, mais superficial. Como exemplo, temos as repetições das mesmas cidades em Livros para rapazes e $A$ Carteira.

Sobre isso, Willi Bolle (2015) chama a atenção de que, se, em um texto tradicional e linear, as repetições devem ser evitadas, a fim de não prejudicarem a sua coesão, no hipertexto elas são positivas e imprescindíveis, pois são elas as formadoras dos nós: "são pontos de concentração de energia, tanto sintática quanto semanticamente, tal como as estações de baldeação em uma rede de metrô e trem suburbano" (BOLLE, 2015, p. 95).

Há também um outro tipo de passagem, onde explicitamos as associações de ideias que Benjamin parece buscar. Ou seja, em um quadro, determinado assunto se coloca breve e quase imperceptivelmente, mas, em outro, o mesmo assunto é aprofundado. O exemplo da cor da joia é útil 
nesse caso. Primeiramente, um excerto do quadro As cores:

O mesmo acontecia com as bolas de sabão. Eu viajava dentro delas pela sala e juntava-me ao jogo de cores das cúpulas até elas se desfazerem. Olhando para o céu, para uma joia ou para um livro, perdia-me nas cores. As crianças são suas presas fáceis por todos os caminhos (BENJAMIN, 2013, p. 108) [hiperlink grifado].

Agora, o início do quadro Festas:

A minha mãe tinha uma joia de forma oval. Era tão grande que não podia ser usada no peito; por isso, de cada vez que a usava, punha-a sempre no cinto. Mas só a usava quando ia a alguma festa, e em casa apenas quando eles próprios davam uma. Era uma beleza, com a sua grande pedra cintilante e amarela ao meio, emoldurada por uma série de outras, de tamanho médio e em várias cores - verde, azul, amarelo, rosa, púrpura (BENJAMIN, 2013, p.146-147).

No site, o hiperlink do primeiro quadro oferece uma passagem ao segundo quadro, pois entendemos que o início de Festas pode ser lido como um exemplo de um momento em que a criança se "perde" olhando as cores de uma joia, exatamente como dito em As cores.

Outro quadro da obra que chama atenção é $O$ anãozinho corcunda. Neste quadro, Benjamin recorda de um personagem da literatura alemã, espécie de "bicho-papão" que se esforçava para "fazer mal e pregar peças", assombrando a criança. Quando supostamente o corcundinha a olhava, ela não conseguia dar atenção às suas atividades, caindo ou quebrando coisas. A criança, então, ficava cercada de cacos.

O interessante é que, talvez a única coisa que Benjamin mantivera em todas as versões do livro, o quadro $O$ anãozinho corcunda sempre foi colocado por último. Pelo viés temático, isso parece evidente quando pensamos que o projeto do filósofo tinha como material os cacos históricos, deixados de lado pela escrita da história tradicional. Assim como a criança fica cercada de cacos das coisas quebradas, a história também produz seus cacos próprios, que são preteridos e ficam abandonados, esquecidos.

Nesse sentido, o Corcundinha encerra o livro, pois parece carregar em si o próprio esquecimento, como se fosse o autor dos quadros antecedentes, que dizem muito mais daquilo que não é lembrado, daquilo que é esquecido no movimento de lembrar. Além do mais, a voz dessa figura, como diz Jeanne Marie (1994, p.94), "atravessa o limiar do século", ou seja, parece haver aqui um encontro entre a personagem da criança com a 
consciência do adulto, momento único na obra. Esse quadro, então, seria a síntese imagética do pensamento benjaminiano a respeito da memória e, por conseguinte, a síntese de Infância berlinense: 1900.

Por outro lado, o viés narrativo também corrobora para o fato de Benjamin sempre ter tido o cuidado de que o corcundinha encerrasse o livro. Há, ao final, uma série de referências claras aos outros textos da obra, referências que foram transformadas em hiperlinks no site. Observe:

Era assim que o anãozinho aparecia muitas vezes. Mas eu nunca o vi. Só ele é que me via. Via-me no meu esconderijo e diante do poço da lontra, nas manhãs de inverno e diante do telefone no corredor da cozinha, no Brauhausberg com as borboletas e na minha pista de patinação ao som da música da banda. (BENJAMIN, 2013, p. 114).

Já sabemos que o hipertexto é considerado uma estrutura "infinita", pois pode abrir espaço para infinitos links sucessivamente, em uma cadeia que só encerra quando o hiperleitor cansar de ler. Benjamin, com o final da obra, parece construir uma espiral, já que o último quadro volta a vários outros. Assim como a espiral, o livro tem um final, mas que é absorvido por uma ilusão quando colocado em movimento. Esse movimento é a própria leitura, e a ilusão é dada pelo corcundinha. Além disso, essa volta aos seis quadros anteriores, a saber, Esconderijos, A lontra, Manhã de inverno, O telefone, Caça às borboletas e Duas charangas, não é uma volta ao mesmo ponto, como em um círculo, mas acontece em um outro momento, como uma espiral. Assim, também pelo caráter hipertextual que a obra possui, não poderia haver outro lugar para o corcundinha que não fosse o final.

Os leques, por sua vez, são os hiperlinks mais recorrentes no literateias.com.br, que abrem para diversas possibilidades de quadros. Assim, o hiperleitor não tem mais uma passagem direta de um quadro a outro, mas uma mediação, onde se revelam possibilidades de escolha de um caminho, como na Figura 1. 
Figura 1 - Captura de tela do site www.literateias.com. $b r$

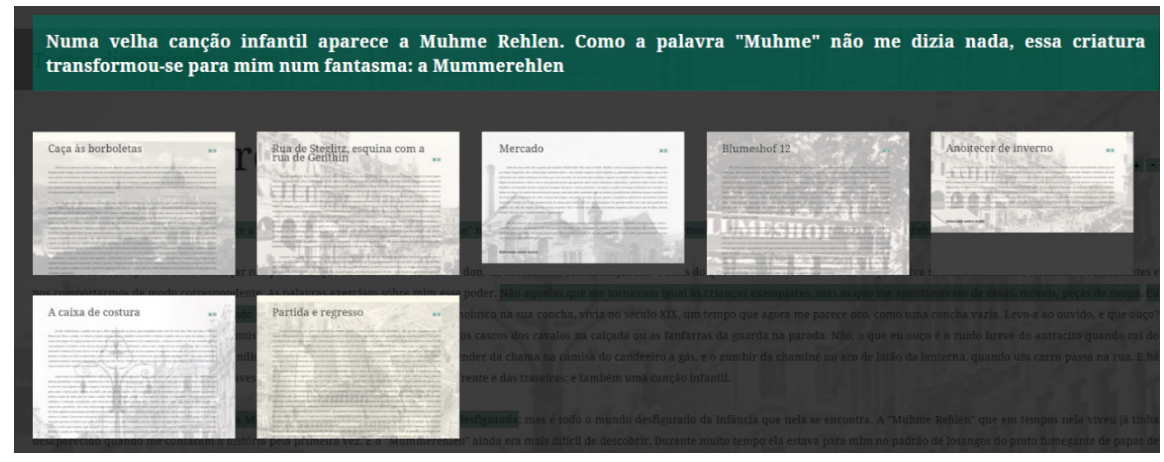

Fonte: literateias.com.br

Esses leques foram construídos baseados, majoritariamente, nos eixos temáticos que estruturam Infância berlinense: 1900. Assim, unimos, por exemplo, em uma constelação, os diversos quadros que se referem a uma ordem social que opõe a burguesia ao proletariado; outra constelação formou-se a partir da importância do sentido tátil no livro; em uma terceira, reuniram-se os elementos oníricos e mágicos presentes em diversos quadros. Os grupos formados podem sofrer alterações, com o acréscimo ou a supressão de quadros, já que a arquitetura hipertextual permite esse caráter movediço. Além disso, outras constelações podem ser sugeridas pelos leitores ou mesmo pensadas nas diversas leituras que o site propõe.

Por questão de espaço, aprofundaremos apenas duas constelações. A primeira foi formada a partir da mímesis na linguagem, por ser esse um conceito importante em Walter Benjamin; a segunda, que denominamos aqui como sendo a constelação da periferia, reuniu quadros que revelam tanto o lugar marginal quanto o olhar controverso da criança burguesa.

Benjamin chama a atenção de que, desde "a vida dos antigos", o pensamento mimético é imprescindível na interpretação do mundo, como a posição dos astros, por exemplo, mas que esse pensamento vai perdendo sua força, ao longo dos séculos, para outro, científico e racionalista. A consequência imediata deste fato é de que a mímesis, na modernidade, vai se concentrar na esfera da linguagem. Benjamin refuta a ideia saussuriana da arbitrariedade do signo, defendendo que a linguagem possui, desde 
sua gênese, um caráter mimético, e a escrita muda ao longo da história, perdendo seu lado imagético, mas mantendo a esfera semelhante e simbólica: "A escrita transformou-se assim, ao lado da linguagem oral, num arquivo de semelhanças, de correspondências sensíveis” (BENJAMIN, 1987, p. 111).

Não é por acaso que quem expõe mais visivelmente os traços miméticos na linguagem é a criança, em seu aprendizado. A criança não só aprende a falar imitando os sons que escuta, mas percebe na linguagem, em um primeiro momento, apenas sons a serem explorados, já que desconhece o sentido de muito do que é dito. Como um poeta, a criança de Infância berlinense: 1900 brinca com as palavras, buscando conhecê-las, desvendá-las. Por isso a metáfora do labirinto é bastante recorrente no livro quando se trata de leitura: porque a criança entra nesse universo desconhecido como um detetive, não temendo perder-se para aprender. Sobre isso, Gagnebin afirma:

Nas suas lembranças de criança, Benjamin narra como ele costumava assimilar as palavras que não tinha "compreendido"; ele as transformava em cartas-enigmas e as mimava, ele as representava como charadas. (...) Para a criança, as palavras não são signos fixados pela convenção, mas, primeiramente, sons a serem explorados (1997, p. 99).

Dessa forma, buscou-se reunir em uma constelação específica os quadros com todos esses trocadilhos ou mal-entendidos tão evidenciados na obra. Esse hiperlink foi criado buscando ressaltar o esforço de Benjamin em mostrar o caráter material da linguagem. A constelação formada agrupou oito quadros de Infância berlinense: 1900, ou seja, quase um quinto do livro. Reproduzimos aqui apenas dois, os quais julgamos mais representativos: A Caixa de Costura e A Mummerehlen, respectivamente.

E muito gostávamos nós de nos apoderar da pequena coroa que nos coroava às escondidas. Quando a enfiava no dedo compreendia o modo como as criadas tratavam a minha mãe. Queriam dizer "gnädige Frau", mas, como mutilavam a primeira palavra, durante muito tempo pensei que elas diziam "Näh-Frau". Não seria possível inventar um título que me revelasse de forma mais evidente todo o poder da minha mãe (BENJAMIN, 2013, p. 109).

Numa velha canção infantil aparece a Muhme Rehlen. Como a palavra "Muhme" não me dizia nada, essa criatura transformou-se para mim num fantasma: a Mummerehlen. 
Em boa hora aprendi a me disfarçar nas palavras, que de fato eram nuvens. O dom de reconhecer semelhanças não é mais do que uma fraca reminiscência da primitiva necessidade de nos tornarmos semelhantes e nos comportarmos de modo correspondente. As palavras exerciam sobre mim esse poder (BENJAMIN, 2013, p. 101-102).

No primeiro fragmento, a criança - que, mesmo burguesa, está afastada da ordem de domínio e subserviência - não entende quando as criadas chamam sua mãe por "gnädige Frau", ou seja, "minha senhora" 2 . Como o universo da costura está mais próximo do menino, que observa, fascinado, a mãe costurando, ele entende "Näh-Frau", ou seja, "senhora da costura".

No segundo excerto, Benjamin desenvolve a necessidade que temos de produzir semelhanças para guiar nossos comportamentos. Para além disso, explica que é na linguagem que a criança encontra esse jogo, exemplificando com o trocadilho do título: "Muhme" significa "tia" em alemão arcaico, desconhecido para a criança, que une essa palavra ao nome próprio, que adquire um tom fantasmagórico e assustador.

Esse último excerto ajuda-nos a compreender o conceito de $m i^{-}$ mesis em Benjamin, que a enxerga não como mera imitação, mas sim pertencente a uma dimensão simbólica. Ou seja, a mímesis pressupõe sempre duas coisas que possuem, entre si, uma semelhança escorregadia, trazida à luz como um lampejo. Quase da mesma forma que a imagem dialética, que possui, em sua constituição, o esquecido e o lembrado, a mímesis possui o símbolo e o interpretado. Sobre isso, Gagnebin (1997, p.98) afirma: "A atividade mimética sempre é uma mediação simbólica, ela nunca se reduz a uma imitação".

Por fim, formou-se outro leque com a reunião de textos que lançam a criança para situações ou espaços periféricos. São lugares marginais, que os adultos da família não frequentam ou não se importam, como os arredores do jardim, a varanda ou o quarto dos empregados. Mas, ainda nessa constelação, encontram-se textos que explicitam o olhar atento da criança para o não-óbvio, o inesperado, como os pedestais das estátuas, os vassalos que coroam os soberanos e os utensílios de cozinha comuns, por exemplo. Assim, esse hiperlink reúne sete quadros, a saber, A coluna da vitória, Festas, Tiergarten, Um fantasma, Rua de Steglitz, esquina com a rua de Genthin, Blumeshof 12 e A Mummerehlen. Consideramos, nessa leitura hipertextual, que os sete quadros trazem esse questionamento da tradição elaborado conscientemente pelo narrador adulto próximo da ide- 
ologia marxista, que olha a criança burguesa já, de certa maneira, estrangeira, estranha ao seu núcleo social. Dizendo de outra forma, como a criança está restrita à experiência burguesa, sendo desimportante aos outros, ela busca a si mesmo nesses espaços que os adultos também menosprezam. Com isso, ela possui um olhar tangencial para os "resquícios". Para ilustrar esse leque, reproduz-se aqui dois excertos, retirados de Rua de Steglitz, esquina com a rua de Genthin e Um fantasma, respectivamente:

E eu retribuía com olhares de admiração por elas [as criadas]. Em geral eram figuras fisicamente mais imponentes do que as senhoras que serviam, e acontecia que o salão lá dentro, apesar da mina e dos chocolates, não me dizia tanto quanto o vestíbulo, onde a velha ajudante me aliviava da carga do sobretudo à chegada, e me enfiava o boné na cabeça à saída, como se me quisesse dar a sua bênção (BENJAMIN, 2013, p. 85) [hiperlink grifado].

Uma das nossas criadas fica ainda um pouco ao portão de grades que dá para uma das alamedas, não sei qual. $\underline{O \text { grande jardim, por cuja }}$ periferia deixada ao abandono eu tinha andado, já está fechado para mim. Chegou a hora de ir para a cama (BENJAMIN, 2013, p. 103) [hiperlink grifado].

Em síntese, é por essa constelação que Benjamin evidencia seu projeto social, muito menos saudosista, muito mais histórico. Lembremos que o filósofo buscou construir no seu projeto das Passagens uma reescrita da história por uma espécie de "colagem" de notas preteridas de jornal sobre Paris: os restos que a história produz e que dizem tanto sobre ela. E é por essa periferia que o autor busca criticar a burguesia, classe social que conheceu tão bem, e que, por isso mesmo, desvinculou-se.

Quando relacionamos as constelações, podemos perceber um diálogo entre elas. Enquanto nos quadros que expõem o caráter mimético da linguagem, é a criança que olha para o mundo dos adultos, buscando dar-lhe sentido pela língua, na constelação da periferia isso se revela ao contrário, pois é o adulto que olha a sua criança e busca, através dela, trazer à tona o universo burguês. Ou seja, as constelações se mostram, de certa forma, opostas e complementares, pois a criança, que ainda não é dotada de plena razão, choca-se com a língua em sua materialidade; no entanto, a representação crítica das características burguesas do início do século XX também só é possível porque existe um adulto dotado de razão e que é capaz de olhar a criança pelo viés crítico. Por fim, é o corcundinha 
que oferece esse encontro entre adulto e criança, pois é ele que está amedrontando as diversas memórias de infância, mas, concomitantemente, é o símbolo do esquecimento - esquecimento do adulto para com essas mesmas memórias. Atravessando o limiar dos séculos, o anãozinho corcunda é a ponta que une o olhar do adulto com o olhar da criança, como em um espelho no qual cada um vê a imagem do outro refletida.

Claro que essa interpretação também pode ser feita quando Infância berlinense: 1900 é lida no papel, mas a construção dos hiperlinks e de constelações e o posterior diálogo entre elas permite que isso seja evidenciado. Dizendo de outra forma, a mudança de suporte e a construção de hiperlinks suscitam novas intepretações. O leitor-construtor relê e volta a ser um leitor-intérprete. 


\section{RESTLESS NARRATIVE OF THE INFANCE IN MO- DERNITY: Berlin Childhood around 1900 by Walter Benjamin}

\section{ABSTRACT}

This study has Berlin childhood around 1900, by Walter Benjamin, as its object. The book contains 42 imagetic frames, in which the philosopher aims to depict German bourgeoisie in the beginning of the twentieth century from the perspective of the child he once was. Nonetheless, the author forsakes the traditional and linear autobiographic project, on the basis that memory is not cohesive, and that past is always articulated. In this way, the narrative Benjamin builds in Berlin childhood around 1900 is a constelational, fragmented and discontinous one, which can be read in a hypertextual fashion. Thus, this study aimed at developing the hypertext narrative in this book, associating its diverse images. For that, we created the web site literateias.com.br, where the book has been made available with hyperlinks that unite the frames with each other. We also developed the idea that this discontinuous narrative is a hallmark of the modern individual, who is uncentered and fragmented, and who arises still in the nineteenth century. It can be concluded, finally, that hypertext also occurs in printed text, and that it is characteristical of the questionings brought about by modernity, such as the end of the grand narratives. The difference is that current hypertexts own an ideal support, namely, the computer's screen, which boosts the resources and the associations that constitute them. In this sense, the construction of the web site literateias.com. br has proven to be fundamental, since it elicited the hypertextual character of Berlin childhood around 1900 while at the same time bringing new breath to Benjamin's work, which can be reinterpreted in light of this new support.

KEYWORDS: Walter Benjamin. Hypertext. Modern narrative. Reading. literateias.com.br. 


\section{REFERÊNCIAS}

BARRENTO, João. Comentário sobre a edição de Infância Berlinense: 1900. In: BENJAMIN, Walter, Infância berlinense: 1900. Belo Horizonte: Autêntica Editora, 2013.

BENJAMIN, Walter. Infância berlinense: 1900. Tradução de João Barrento. Belo Horizonte: Autêntica Editora, 2013.

. O Narrador. In: et al. Textos escolhidos. São Paulo: Abril Cultura, 1983

. A doutrina das semelhanças. In: Magia e Técnica, Arte e Política. Tradução de Sérgio Paulo Rouanet. São Paulo: Brasiliense, 1987.

BOLLE, Willi. A metrópole como hipertexto: a ensaística constelacional no projeto das Passagens, de Walter Benjamin. In: MACHADO, Carlos Eduardo, MACHADO JR., Rubens \& VEDDA, Miguel (orgs.). Walter Benjamin: experiência histórica e imagens dialéticas. São Paulo: Unesp, 2015.

CHAVES, Ernani. Sexo e Morte na Infância Berlinense, de Walter Benjamin. In: SELIGMANN-SILVA, Márcio (org.). Leituras de Walter Benjamin. São Paulo: FAPESP, 1999

COSCARELLI, Carla Viana. Da leitura de hipertexto: um diálogo com Rouet et al. In: ARAÚJO, Júlio César \& BIASI-RODRIGUES, Bernardete (orgs). Interação na Internet: novas formas de usar a linguagem. Rio de Janeiro: Lucerna, 2005.

DIDI-HUBERMAN, Georges. O que vemos, o que nos olha. Tradução de Paulo Neves. São Paulo: Editora 34, 2010.

GAGNEBIN, Jeanne Marie. História e Narração em Walter Benjamin. São Paulo: Perspectiva: Campinas: FAPESP, 1994.

Lembrar escrever esquecer. São Paulo: Editora 34, 2009.

Imago, 1997.

Sete Aulas Sobre Linguagem, Memória e História. Rio de Janeiro:

HALL, Stuart. A identidade cultural na pós-modernidade. Tradução de Guacira Lopes Louro \& Tomaz Tadeu da Silva. Rio de Janeiro: Lamparina, 2015.

LÉVY, Piérry. As tecnologias da inteligência: o futuro do pensamento na era da informática. São Paulo: Editora 34, 1993.

KOMESU, Fabiana. Pensar em hipertexto. In: ARAÚJO, Júlio César \& BIASI-RODRIGUES, Bernardete (orgs). Interação na Internet: novas formas de usar a linguagem. Rio de Janeiro: Lucerna, 2005. 
PINHEIRO, Regina Cláudia. Estratégias de Leitura para a Compreensão de Hipertextos. In: ARAÚJO, Júlio César \& BIASI-RODRIGUES, Bernardete (orgs). Interação na Internet: novas formas de usar a linguagem. Rio de Janeiro: Lucerna, 2005.

\section{NOTAS}

${ }^{1}$ A versão do livro utilizada nesse trabalho é a chamada "versão de última mão", traduzida para o português por João Barrento e publicada pela Editora Autêntica, cujo título é Infância berlinense: 1900, e não Infância em Berlim por volta de 1900, outra versão, traduzida por João Carlos Martins Barbosa, e publicada pela Editora Brasiliense.

${ }^{2}$ Esta e as traduções que seguem são de João Barrento (Autêntica, 2013).

Recebido em: 31/01/2017

Aceito em: 06/06/2017 